\title{
Dimensiones temporal y musical en la creación de Pablo Palazuelo
}

\section{Temporal and musical dimensions in Pablo Palazuelo's work}

\author{
Pedro Ordóñez Eslava \\ Universidad de Granada. Dpto. de Historia y Ciencias de la Música \\ eslavap@ugr.es
}

Recibido: 21 de septiembre de 2011

Aprobado: 24 de octubre de 2011

\begin{abstract}
Resumen
El objetivo de este artículo es indagar por un lado en la dimensión temporal que adquiere la creación plástica de Pablo Palazuelo - del que se realiza una breve revisión bio-bibliográfica- ya desde sus primeros años en París a finales de la década de los cuarenta hasta sus últimas piezas a comienzos del siglo XXI; por otro lado y desde la convicción de su pertinencia, se analiza la presencia de lo musical en el corpus del pintor madrileño precisamente como materialización de dicho parámetro temporal. Esta presencia se observa desde la óptica que define la metodología semiológica de Jean-Jacques Nattiez dividida en tres niveles hermenéuticos: poiético o conceptual, neutro o gráfico y estésico o receptivo.

A fin de subrayar este vínculo interdisciplinar entre pintura y música, proponemos un acercamiento al ciclo El número y las aguas y su traslación sonora efectiva por parte del compositor Frederic Nyst. Palabras Clave: Pablo Palazuelo, Arte y Tiempo, Arte y Música, Estética, Abstracción.
\end{abstract}

Ordóñez Eslava, P. 2011: Dimensiones temporal y musical en la creación de Pablo Palazuelo. Arte, Individuo y Sociedad, 24(1), 119-134

\begin{abstract}
The aim of this text is at first to study in depth the temporal dimension of Pablo Palazuelo's workafter making a bio-bibliographical revision- since his years in Paris at the end of the 40's to his last pieces at the begin of XXIst century; second, and with the conviction of his pertinence, I seek to analyze the presence of music in the corpus of the Spanish painter, just as a visible example of this temporal fact. I'll try to study this sonic presence with the aid of the semiological methodology defined by Jean-Jacques Nattiez, divided in three levels: poietic or conceptual, neutre or graphic and esthesic or receptive.

In order to make this link between music and painting brighter, I propose the study of the cycle $E l$ número y las aguas and his sonic translation by the composer Frederic Nyst.
\end{abstract}

Key Words: Pablo Palazuelo, Art in Time, Art and Music, Esthetic, Abstraction.

Ordóñez Eslava, P. 2011: Temporal and musical dimensions in Pablo Palazuelo's work. Arte, Individuo y Sociedad, 24(1), 119-134

Sumario: 1. Introducción, 2. Dimensión temporal y poiética creativa, 3. Grafías sonoras, $3.1 \mathrm{La}$ traslación sonora efectiva, 4. Estesis de Palazuelo, 5. A modo de conclusión. Referencias 


\section{Introducción}

La conciencia, los momentos de la quietud del cuerpo, en otros momentos eufórico e impulsivo. El sentimiento de musicalidad durante la evolución de la línea. La sorpresa que produce el cantar de un color al lado de otro, ambos imaginados. La tensión exultante y la calma, el tiempo diferente, la duración, la memoria independiente. (Palazuelo \& Power, 1995, 56; Bonell, 2006, 131).

Con estas palabras, el pintor madrileño Pablo Palazuelo (Madrid, 1915-2007) nos muestra su posición ante el acto de creación artística, acto que, por otro lado, alcanza cualidades místicas para cuya definición el lenguaje adquiere un matiz musical y una clara dimensión temporal.

En este artículo es nuestro objetivo acercarnos precisamente a estas dos dimensiones íntimamente relacionadas, tiempo y música, en la extensa y asimismo muy relevante producción de este creador plástico; y lo haremos no sólo desde una perspectiva histórica, es decir, desde aquella que considera estas dimensiones a lo largo de la producción palazueliana, sino también desde su aplicación efectiva, visible en aquellas experimentaciones gráficas que se acercan a la forma simbólica de representación de lo musical, es decir, a la notación.

Como nos dice J.-Y. Bosseur,

De nombreux plasticiens (...) ont eux-mêmes tiré parti, à leur manière, de cet espace codifié de signes spécifiques (destiné à rester partiellement secret pour les non-initiés) que représente la partition. Entrecroissant données symboliques et graphiques, la notation musicale présente un intérêt très particulier pour le peintre, dans la mesure où son code de lecture ne lui est pas nécessairement familier. (Bousseur, 1998, 151).

Efectivamente, la representación gráfica del sonido musical atrae al artista plástico; Palazuelo muestra este interés ya desde sus años en París y, como veremos, lo materializa en no pocas piezas de su catálogo pictórico. Es ésta una forma de vínculo interdisciplinar que proviene de una inquietud propia, es decir, de una actitud abierta y permeable a expresiones de otras disciplinas, y como tal debe ponerse en relación con una concepción del hecho creativo también visible en otras voces de la creación artística contemporánea (Johnson, 2002, Arnaldo, 2003, Roy-Gerboud, 2009, Vergo, 2010).

Antes de iniciar el estudio, es imprescindible acercarse a la trayectoria biográfica del pintor puesto que ofrece detalles sustanciales que muestran una sensibilidad notable hacia la música, sensibilidad que se traduce en una conciencia precisa de las posibilidades que su propia obra ofrece como soporte a partir del que construir un discurso sonoro.

Pablo Palazuelo es una personalidad artística de relevancia contrastada en la denominada abstracción geométrica. A su formación inicial en la Escuela de Artes y Oficios de Madrid debe sumarse la estancia en la School of Arts and Crafts de Oxford, todo ello antes de la Guerra Civil española. Tras el conflicto, centró su atención decisivamente en la pintura. A finales de los años cuarenta da el paso internacional y se instala en el Colegio de España de París, aunque algunos críticos aún lo situaran en 
Madrid en 1952 y lo definieran como uno de los artistas que 'trabajan desparramados por España [y] que pugnan por hallazgos personales' (Gullón, 1972, 51). En la residencia del 14ème parisino compartirá experiencias con Eduardo Chillida, entre otros artistas 'obligados a marcharse fuera del país' (Calvo Serraller, 1985, 68). En la capital francesa tomará contacto con protagonistas del arte contemporáneo como el matrimonio Maeght y el artista Ellsworth Kelly y encontrá, por tanto, el marco idóneo para desarrollar de forma más adecuada su creación. Durante la década de los cincuenta, su producción comienza a alcanzar proyección internacional: además de la concesión del Premio Kandinsky (1952), su participación en la exposición Young Spanish Artists (1953) en el Museo Gunggenheim de Nueva York y su primera exposición individual en la Galería Maeght parisina (1955), debe considerase la concesión del V Premio Internacional Carnegie del Pittsburgh International Museum of Art, centro donde expuso tres años antes. Ya en 1969 regresa definitivamente a España, tras una primera visita en 1963, habiendo constituido un corpus pictórico sólido y conceptual. En 1973 tendrá su primera exposición individual española tras la vuelta del exilio -en la Galería madrileña Iolas Velasco- para, casi una década después, recibir la Medalla de Oro de las Bellas Artes (1981). Ya durante los años noventa, Palazuelo recibe la una primera muestra de reconocimiento a su carrera creativa a través de la exposición retrospectiva del Museo Nacional Centro de Arte Reina Sofía de Madrid (1995) y del Premio Nacional de Artes Plásticas en 1999. Poco antes de su desaparición en 2007, recibe el Premio Velázquez de Artes Plásticas (2004), y se realizan varias exposiciones retrospectivas en el Museo Nacional Centro de Arte Reina Sofía, el Museo d'Art Contemporani de Barcelona y el Museo Guggenheim de Bilbao, entre 2005 y 2007.

La creación plástica de Pablo Palazuelo dibuja una trayectoria en la que la abstracción juega un papel esencial desde su comienzo. Aunque inicialmente el pintor madrileño se movió en una figuración tímidamente cubista -como puede observarse en su participación en las exposiciones de La joven escuela de Madrid (Galería Bucholz, entre 1945 y 1947) - la pintura abandona cualquier referencia figurativa ya en 1948: en este año Palazuelo interviene en el Homenaje a Paul Klee que organizan la Galería Palma y la Librería Clan de Madrid. A través de esta muestra, se acercará ya de forma indeleble en su pensamiento plástico a la producción del pintor suizo. Asimismo, 1948 es el año de partida a París, ciudad también esencial en la trayectoria vital y estética del artista madrileño. Es a partir de este momento cuando Palazuelo se introduce en un pensamiento abstracto que estará también definido por una atención constante hacia la música, su representación gráfica y su consideración poética.

En cuanto a la recepción crítica e historiográfica de esta trayectoria creativa, la figura del pintor madrileño se ha visto inicialmente adscrita a la segunda oleada que inundó la denominada Escuela de París, como nos cuenta Valeriano Bozal:

A los [artistas] que viven alli, los que forman la llamada Escuela de París, se añaden otros que llegan a la capital francesa por motivos políticos o artísticos y después, tras la Segunda Guerra Mundial, un grupo de jóvenes que romperán con la tradición académica que se habia impuesto en la Península: Palazuelo, Chillida, Sempere, Tàpies (...) (Bozal, 2000, 122). 
De entre ellos, destaca rápidamente Palazuelo, que incluso 'tuvo una considerable influencia sobre ellos [Chillida y Sempere]' (Bozal, 2000, 346), puesto que 'había empezado a pintar algo antes y, además, tenía en 1948 una formación más sólida' (Bozal, 2000, 346).

A pesar de su extensión, es interesante citar lo que Bozal comenta acerca del perfil de Palazuelo:

En los años cincuenta Palazuelo acentúa el protagonismo de los valores geométricos y ritmicos, sin abandonar nunca aquellos elementos que eran propios de la pintura parisina, fundamentalmente la plasticidad de sus imágenes. Esta orientación se hace cada vez más compleja y sutil (...) jugando con las aproximaciones, la calidad cromática, la apertura de los motivos para introducir ritmos especificos (...).

Palazuelo no está inmerso en una investigación como la del Equipo 57, bien al contrario, el sentido de sus ritmos posee un sentido lírico y transcendental que (...) enlaza con el pensamiento oriental. Los colores nunca se plantean en la planitud que permite resolver los problemas geométricos, son colores con un valor estético, contrastados estéticamente, iluminados, cuando la luz juega en ellos un papel, estéticamente.

A partir de su vuelta a España (...) [y] como si fueran obras musicales, las pinturas exhiben en su superficie signos que articulan ritmos plásticos, (...) sin referencias concretas. (...) La única referencia de los signos es el ritmo que crean. (Bozal, 2000, 349-350).

De esta breve semblanza es muy interesante destacar términos como ritmo, signo, entre otros; estos conceptos aparecerán a lo largo de este trabajo y encontrarán un contexto preciso en el marco de las obras analizadas.

La recepción historiográfica del Palazuelo más reciente debe construirse a partir de las numerosas exposiciones que sobre su obra se han realizado. El volumen que ofrece el mayor aporte crítico es el Catálogo de la titulada Palazuelo. Proceso de trabajo, celebrada entre diciembre de 2006 y febrero de 2007 en el Museo de Arte Contemporáneo de Barcelona (MACBA) y editado por este museo y por el Guggenheim de Bilbao - donde también se celebró esta exposición entre marzo y junio de 2007. Esta exposición recoge muestras de toda la carrera artística del pintor madrileño en lo que supone la mayor retrospectiva realizada hasta el momento. En cuanto al componente estrictamente ensayístico, este volumen recoge varios artículos y diálogos de, entre otros, Ignacio Gómez de Liaño y Manuel Borja-Villel.

Sin embargo y debido a la ausencia casi total de referencias que contemplen la estrecha relación que el pintor mantiene a lo largo de toda su carrera creativa con la música, ha sido preciso indagar y realizar un estudio detenido sobre la literatura primaria de Palazuelo, literatura recogida fundamentalmente en tres libros: Geometría y visión, una conversación con Kevin Power en la que el crítico desgrana de manera precisa las claves estéticas y las inquietudes del pintor; el volumen Pablo Palazuelo. Escritos, Conversaciones, que recoge, en una edición realizada por el Colegio Oficial de Aparejadores y Arquitectos técnicos de Murcia un amplio compendio de textos propios del pintor; y La Geometría y la vida, un vaciado documental organizado como diccionario terminológico que ha acercado y facilitado de manera considerable 
el hallazgo de información y textos acerca de lo musical en el corpus conceptual de Palazuelo.

A partir de lo consultado en esta literatura secundaria y del análisis realizado es posible destacar ciertos elementos poéticos y técnicos que evidencian una estrecha relación con un pensamiento musical en lo que a su dimensión poética/temporal y gráfica se refiere.

Asimismo, el pintor madrileño construyó un planteamiento plástico complejo y para ello tuvo muy en cuenta la filosofía y el pensamiento de aquellos con los que compartió al menos periodo cronológico, es decir, con sus coetáneos, fundamentalmente. Su conocimiento no vino sólo por la lectura de sus textos sino también por una considerable labor de traducción de publicaciones originales (Jarauta et al., 1998) y de redacción de notas y comentarios a partir de ellas, lo que le llevó a constituir un amplio corpus de escritos y reflexiones. Aunque

Palazuelo no se considera ni poeta ni literato (...) los documentos que él nos ha confiado son, según él mismo los considera, las trazas de una trayectoria a veces intuitiva: se trata todo lo más de notas, borradores, testigos suplementarios $y$ citas del mundo multiforme en el que se apoya para dar forma a sus pensamientos. (Jarauta et al., 1998).

Así, de esta actividad literaria del pintor pueden obtenerse algunas de las claves de su poética y práctica pictóricas; en ellas la dimensión temporal, que es precisamente la que más nos interesa - y que Palazuelo construye a partir esencialmente de las teorías de David Bohm-, logra una notable relevancia. Junto a ella, es también pertinente reseñar la atención que dedica tanto a los procesos matemáticos -desde los textos de Michael Leyton, Roger Penrose y John D. Barrow-o los avances en la física - a partir de la teoría de la complejidad en autores como Roger Lewin - hasta la psicología - desde Carl Jung- y el estudio y conocimiento de la cultura islámica -a partir del islamólogo Henri Corbin-; esta última alcanza gran calado en la poética palazueliana.

Estos intereses muestran un comportamiento permeable, es decir, cada proposición estética que nos ofrece el catálogo de Palazuelo nace de una construcción múltiple y compleja; en ella, como veremos, el tiempo -como duración, ritmo, tránsito- es una cuestión transversal. Es por ello que para su análisis se ha acogido la metodología semiológica de Jean-Jacques Nattiez $(1975,1990,2010)$, que establece tres niveles hermenéuticos en interrelación constante:

1. El primero es el poiético o conceptual, que se establece a partir del discurso del propio Palazuelo, sustentado sobre presupuestos filosóficos específicos. Esta categoría implica aproximarse, desde nuestra perspectiva, al concepto de tiempo en la obra artística y a la consideración que este concepto adquiere en el discurso del pintor. Esta dimensión temporal es un primer paso para ponderar la posición de la música como su materialización directa.

2. El segundo es el neutral o gráfico; en él cabe definirse una relación quizás más obvia, ya que el discurso del propio pintor se objetualiza en la asunción 
de la notación musical como grafía plástica, es decir, se toma la forma de representación musical convencional como punto inicial para la elaboración pictórica: el orden neutral o gráfico se convierte en sí mismo en objeto artístico. Este proceso culmina con una traslación -o traducción-sonora efectiva que será detenidamente analizada.

3. El tercero es el estésico. En este nivel es preciso atender a la forma en que la notion de vouloir, adquiere su dimensión de pouvoir, es decir, cómo se corresponde la intención poiética del creador con el objeto final constituido y con la percepción final que el receptor-visitante, espectador, oyente -obtiene.

\section{Dimensión temporal y poiética creativa}

Comencemos: la obra de Pablo Palazuelo presenta una dimensión temporal que va más allá de la convencionalmente aceptada en la historiografía artística, es decir, de aquélla que se instala en la constatación del transcurso obvio de la creación de la obra y de su posible percepción por el público (Gómez de Liaño, 2007, 17 y ss.). Existe una conciencia minuciosa y un aparato teórico preciso sobre la esencia temporal intrínseca y cualitativa de la obra de arte y de las relaciones que pueden establecerse entre los distintos objetos que la componen, relaciones que a su vez necesitan de tiempo para ser percibidas.

El propio Palazuelo afirma,

Es la duración del presente lo que hace posible la vida, y es el a-hora (...), lo que va con nosotros, por el presente sin término, el presente siempre fruto y semilla. El presente es eterno, es la presencia de lo ilimitado que se mueve con el universo.(Jarauta et al., 1998, 114-116).

Dos ideas pueden extraerse de este breve texto -concluido en enero de 1995- en el que el pintor alude directamente a su concepción del tiempo, ideas que conforman su planteamiento poético y que tendrán además una consecución efectiva en su producción.

La primera de ellas coincide exactamente con la primera frase del párrafo y muestra ya las referencias filosóficas que pueden rastrearse en el corpus poiético del pintor. En esta definición del tiempo como 'duración del presente' debe observarse la apertura del instante presente a lo eterno que parte de la propuesta de David Bohm (19171992); este físico y filósofo norteamericano centró la mayor parte de su carrera en la teoría cuántica, la relatividad y su significado filosófico y fue responsable directo de la asimilación en Occidente del pensamiento de Jiddu Krishnamurti con el que mantuvo una estrecha relación visible a través de sus numerosas entrevistas publicadas (David Bohm y J. Krishnamurti, 1987, 1996, 2006).

Entre las traducciones a que antes se aludía se encuentran precisamente las que realizó de David Bohm y su Thought as a System (Bohm, 1994); es por esto que este 
autor debe ser tenido en cuenta para la comprensión de los textos del pintor madrileño.

Desde finales de 1994 hasta 1997 Palazuelo tradujo y trabajó sobre varios capítulos de este Thought as a System para confeccionar hasta seis entradas en sus notas de estudio (Jarauta et al., 1998, 261-274), bajo títulos, del propio pintor, tan significativos como 'Percepción-Identidad', 'El pensamiento' o 'La individualidad'.

Como es obvio, el vínculo que puede establecerse entre ambos autores va más allá de la reflexión acerca del tiempo; por ahora, sin embargo, es precisamente ésta la que nos interesa para nuestro estudio. En este sentido, David Bohm afirma, en traducción de Palazuelo:

El orden de sucesión es el hecho del cual parte la idea del tiempo y también el orden $u$ órdenes de duración. El orden del tiempo es enteramente imaginado, es un engaño. Todo el pasado y el futuro que podemos conocer se hallan en este momento -son ahora-. No es bueno ver el ahora como un chispazo. El sentido de la continuidad procede del pensamiento porque el cerebro distingue las imágenes que pasan muy rápidamente como algo continuo. El tiempo (...) es una forma de pensar. Sin pensamiento no existe tiempo. (Jarauta et al., 1998).

Son obvias las conexiones intertextuales que pueden establecerse entre este fragmento y el citado de Palazuelo anteriormente, en el que, como ahora puede constatarse, aparecían claras alusiones a términos y conceptos del filósofo norteamericano.

Para completar la referencia filosófica, es interesante el rastro de Xavier Zubiri, en relación con su teoría sobre la temporalidad, de donde se extraía que el ahora es un 'modo del tiempo', es un momento de la 'unidad gerundiva' (Zubiri, 1995, 297) del tiempo. El pintor madrileño no extrae de Zubiri tanto su delimitación del tiempo como su concepto de 'pensamiento sentiente', uno de los fundamentos en el corpus del filósofo a partir de su publicación La inteligencia sentiente de 1980 (Zubiri, 1998) y del que Palazuelo habla ya en una conversación publicada en 1981 (Jarauta et al., 1998, 73-75).

Por último, no puede evitarse, al aludir Palazuelo al concepto de duración, a la definición que de durée réelle realiza Henri Bergson y su muy conocida aplicación a la percepción de una melodía musical; oído como sucesión de notas con una continuidad absoluta, es precisamente este flujo sonoro el que sustenta la propia sensación de sucesión y, por tanto, de melodía. En cada una de las notas está presente la linealidad melódica en toda su extensión (Bergson, 1977, 21).

Esta dimensión temporal de la producción palazueliana nos obliga a una segunda lectura del fragmento citado, como antes anunciaba, que tendría que ver, como conclusión de lo expuesto, con la conciencia de lo eterno inscrito en el presente, esto es, con la confluencia de pasado y presente -y proyección futura- en cada instante de tiempo. Esta confluencia no es sino la sucesión de 'ahoras', que, de esta forma, daría lugar a la conciencia de continuidad, creación del individuo más allá de cualquier categoría temporal física. 


\section{Grafías sonoras}

Pero debemos volver nuestra mirada a la consideración musical, que logra una atención constante en los textos de Palazuelo y que encarna esta dimensión temporal, materializándola de forma decisiva. De hecho, entendida como 'energía que fluye llenando y coagulando todos los espacios del mundo' (Bonell, 2006, 83), el arte sonoro alcanza una presencia ininterrumpida tanto en el planteamiento poiético como en el catálogo creativo del pintor madrileño.

De esta forma, según la segunda categoría semiológica establecida, la noción temporal definida ganará aún mayor claridad en aquellas pinturas en las que la referencia a una posible notación musical es obvia, puesto que muestra al espectador a una 'lectura' plástica que, evidentemente, requiere de tiempo. Esta noción se instala en el segundo nivel neutro.

En 1978 hice una serie de dibujos y gouaches pensando mucho más conscientemente en la posibilidad de una notación musical. Aquellas obras, tituladas Cantoral, eran la expresión de lo que yo entonces creía y aún sigo creyendo posible. Veía el paralelismo entre los signos gráficos y la música porque pensaba que la música se podía transcribir gráficamente por medio de dibujos. (Bonell, 2006, 60).

Efectivamente, este 'paralelismo' alcanza incluso al soporte convencional para la escritura musical, que aparece en algunas piezas del artista madrileño:

Ya desde mis primeros años en París hice algunos dibujos que me sugerían notaciones musicales después de realizados. Se trataba de dibujos espontáneos, compuestos sin ninguna idea musical preconcebida. Después de contemplarlos escribí al pie de algunos: 'Sobre el pentagrama' (Palazuelo \& Power, 1995, 60).

En dibujos como Sobre el pentagrama (c. 1949-1950) y Sin título (1953), la referencia netamente gráfica es obvia, a través de un gesto que pretende emular una notación musical simbólica, una especie de nueva notación que más tarde podrá ser transcrita efectivamente al ámbito sonoro en la experiencia ya de finales de los setenta. De hecho, el pintor parece incorporarse, desde su posición como artista estrictamente plástico, a una práctica que comienza a instalarse en la creación musical, ya desde inicios de los años cincuenta, y que será paso obligado para algunos de los compositores más significativos de la segunda mitad del pasado siglo XX: la notación gráfica (Villa-Rojo, 2003) o 'graphic scores'.

Debemos apuntar la multiciplicidad de tendencias y corrientes diversas que se desarrollan en el marco conceptual de esta expresión. Entre ellas podemos encontrar tanto compositores que emplean nuevas grafías para sonidos de 'nueva catalogación' -John Cage (1912-1992), Sylvano Bussotti (1931) y su Piano piece for David Tudor (1949) o Salvatore Sciarrino (1947)- como artistas plásticos y sonoros que se sienten atraídos por la carga simbólica de la representación gráfica de lo musical -desde el pionero estadounidense Earle Brown (1926-2002) y su December 1952 hasta Joan Brossa (1919-1998) o Josep Ma Mestres-Quadreny (1931) (Villa-Rojo, 2003, 52 y ss.; Ordóñez, 2011, 53-100). 
Todos ellos contemplan la posibilidad de otorgar a una forma de representación sonora un valor plástico propio y autónomo, es decir, atienden a la consecución de una forma simbólica de representación gráfica alejada de la tradicional occidental que obtiene un valor plástico per se, más allá de su interpretación musical.

Así debe plantearse la originalidad plástica de Palazuelo, en el contexto de su residencia en París y en un momento en que aún son pocos los creadores que insertan signos no convencionales de cualquier tipo sobre el pentagrama. Entre estos pocos es inevitable la alusión a un pintor ruso cuyo posicionamiento estético influye de forma decisiva en una etapa inicial de la actividad palazueliana: Wassily Kandinsky. Él también, a inicios del siglo pasado, proponía la convergencia de poesía, música y pintura en creaciones como el álbum Klänge (Sonidos), publicado por Piper Verlag en 1913 y, aún antes, Der gelbe Klang (1909); esta pieza escénica fue de hecho objeto de estudio de Palazuelo, puesto que trabajó en unos decorados para su interpretación en París -Étude pour 'Sonorité jaune' de Kandinsky (1954) (Gómez de Liaño et al., 2007, 60 y ss)-, proyecto que nunca llegó a ejecutarse.

\subsection{La traslación sonora efectiva}

Sin embargo, no es hasta finales de los años setenta cuando el contacto con la creación musical se materializa en dos direcciones, fundamentalmente, pasos que nos conducirán a la traslación efectiva de la abstracción palazueliana al dominio de lo estrictamente musical y sonoro. Dicha traslación debe ser tomada como una materialización de esta segunda categoría, gráfica, en el análisis tripartito que venimos desarrollando de la dimensión temporal -y musical- en la creación palazueliana.

La primera de estas direcciones aludidas es la producción de la serie Segundo Cantoral I-IV (1978) (Díaz Cuyás, 2000, 23).

En los Cantorales pretendo configurar el espacio rítmicamente, midiéndolo según el tiempo. El espacio-tiempo es portador de la pintura, y también de la música y de su notación. (Bonell, 2006, 156).

Así se expresa Pablo Palazuelo en 1978. Precisamente en el ciclo Segundo Cantoral, el pintor muestra un planteamiento gráfico que recuerda ineludiblemente a la forma de representación gráfica del canto en escuelas notacionales como la aquitana o la catalana durante los siglos XI y XII. Precisamente, en este momento aún prematuro en la tradición musical occidental no se utiliza aún ninguna referencia lineal. No en vano, el ciclo se titula Cantoral, lo que puede entenderse como una mención directa a la definición literal de este término: 'libro grande de coro, en cuyas hojas, generalmente de pergamino, están escritos los salmos y antífonas que se cantan en el coro, con sus notas musicales'.

Sobre fondo negro la serie Segundo Cantoral muestra entre tres y cinco campos sígnicos - depende del lienzo en que fijemos nuestra atención. En ellos aparecen gestos gráficos de color blanco que parecieran seguir una linealidad temporal y musical. Decimos musical puesto que, aunque cabría pensar quizás en una posible raíz sígnica de naturaleza idiomática, esto es, relacionada con algunas lenguas que mantienen un 
gesto gráfico parecido -como el árabe clásico o el hebreo-, es decisivo el propio título del Ciclo: el cantoral, que mantiene esta acentuada horizontalidad de los trazos que hace pensar precisamente en la conformación de sistemas notacionales. En contraposición, surgirán ya a inicios de los años noventa series de una marcada verticalidad, como Nigredo, Arrán o Vinculum Amoris; estas piezas, sin embargo, mantendrán una estrecha relación con el pensamiento estructural musical a través de conceptos como energía, vibración y ritmo, en un plano poético más complejo.

Este tipo de proposiciones plásticas quiere mostrar, en un dominio conceptual y filosófico que va más allá de una 'lectura' musical, una suerte de escritura previa al sonido, 'un lenguaje antes del lenguaje' (Díaz-Cuyás, 2007, 20). Se trata de una forma de trabajar con la materia sonora anterior a la propia materia, el estudio de un signo 'que es ornato, que es previo a la propia figura, que sería previo al nombre mismo' (Ibíd.). Existe, según Ignacio Gómez de Liaño, una intencionalidad dirigida a hacer 'visible lo invisible, o hacer legible lo ilegible. Una escritura cifrada para que cada uno, de algún modo, descubra la cifra' (Gómez de Liaño, 2007, 18), en la conformación precisamente de un 'alfabeto musical'.

La segunda dirección que toma la producción de Pablo Palazuelo a finales de la década de los setenta es aquella que se dirige, desde el trabajo ya de forma estrecha con el compositor Frederic Nyst, hacia la posibilidad de trasladar al ámbito musical su serie pictórica El número y las aguas -en su segundo y tercer periodo. Nacido en 1939 en Lieja, Nyst estudia con el compositor Henri Pousseur en el Centro de Investigaciones Musicales de Valonia, donde es posteriormente responsable de un Taller de música electroacústica y de música e informática. En 1974 se traslada a París, donde continúa sus estudios en el Centro de Estudios Matemáticos y de Automática Musical (CEMAMU), fundado por Iannis Xenakis en 1966 (Jarauta et al., 1998, 79). Esta es la única información biográfica localizada sobre este compositor verdaderamente poco conocido aunque fundamental para el trabajo de traslación sonora que nos ocupa.

La serie El Número y las aguas de Palazuelo integra por un lado diecinueve cuadros realizados entre 1978 y 1993 y, por otro, el ciclo Notación. Estudio para la carpeta del disco 'El número y las aguas'(1981-1984). Esta obra compuesta muestra una vez más la relevancia que en la obra de Palazuelo alcanza el trabajo en familias o series. Como él mismo afirma:

Yo agrupo mis cuadros porque la proximidad fisica de los varios integrantes de un grupo o familia muestra más claramente un proceso de transformación continua e irreversible que en su desarrollo desborda los límites de cada obra individual. Se trata pues, como dice Prigogine, 'de un sistema de organizaciones perpetuamente activas que se disipan, se re-forman, y nunca se detienen' (Power, 2005, 19).

La construcción de este Ciclo supone para el pintor la posibilidad de ahondar de forma efectiva en una iniciativa observada de forma incipiente tanto en los dibujos de los años cincuenta como, de manera mucho más obvia, en los cuadros de la serie Segundo Cantoral: la posibilidad de concebir su gesto gráfico como un objeto susceptible de ser 'leido', 'ejecutado', 'interpretado' en forma de sonidos, es decir, tomar 
su producción plástica como una partitura musical. Siguiendo su propia expresión, se trata de 'dibujar partituras' (Jarauta et al., 1998, 77).

Esta relación interdisciplinar parte no obstante de una clara conciencia de las circunstancias en las que puede desarrollarse. Respecto a la posibilidad de intervenir desde el exterior sobre un objeto artístico precedente, el propio Palazuelo asume y admite las vicisitudes que puedan surgir y su posibilidad final. Escribe de forma precisa:

La imagen dibujada es un conjunto autónomo de signos que tiene su propia dinámica interna, regida por una coherencia global y significante, y que constituye un sistema que posee su propia semiología. La obra dibujada y así estructurada es un organismo, una configuración viviente, puesto que contiene en potencia la capacidad de admitir una intervención exterior -una manipulación-, la cual puede activar su dinamismo interno a fin de que éste desarrolle los procesos de transformación continua, de sus metamorfosis. (...) La partitura de El número y las aguas es una estructura, un dibujo geométrico continuo y concebido como un sistema abierto. Este cuerpo geométrico engloba en su unidad una multiplicidad perceptible (Jarauta et al., 1998, 79-80).

Como expresa el propio Nyst, su objetivo es 'desarrollar un discurso musical basándome en los signos de esa obra, organizar los segmentos en el tiempo, añadir los algoritmos del compositor a los del pintor, ésta es la tarea a la que me he dedicado últimamente' (Palazuelo \& Nyst, 1986, 57). Uno de los detalles más interesantes es precisamente la pregunta que se formula el propio Nyst, cuestión de la que participamos plenamente: '¿Pueden dos personas con similitudes respecto a los problemas de 'Creación' pero de diferentes disciplinas de expresión aproximar sus respectivas sintaxis?' (Ibíd.).

El proceso técnico a través del que Nyst constituye la partitura real desde la obra palazueliana parte de la posibilidad de trabajar con el denominado UPIC, siglas de la Unité Polyagogique Informatique, Unidad 'Poliagógica' Informática -en traducción literal-. Este instrumento, diseñado por el compositor Iannis Xenakis en 1977 en el marco del Centre/Équipe d'Études de Mathématiques et Automatiques Musicales (CEMAMU), leía cualquier tipo de trazo gráfico y lo 'traducía' literalmente en estímulos sonoros electrónicos (Villa Rojo, 2003, 52). Así lo explica el propio Nyst:

El UPIC permite dibujar sobre una mesa gráfica parámetros que definen un sonido. Una vez pasados a números, estos dibujos entran en la memoria del ordenador del sistema. De esta manera se pueden introducir en la memoria formas de periodos y cubiertas de sonidos (evolución del valor de intensidad de una señal en el tiempo). Estas formas de periodos y estas cubiertas sonoras componen un 'menú' y permiten la apertura de una página musical sobre la que se pueden dibujar los arcos de sonido. (...) El objetivo a alcanzar es aprehender, codificar y explicitar un discurso musical que surge de esas 'aguas' (Palazuelo \& Nyst, 1986, 58).

Para poder emplear este instrumento electrónico de traslación sonora, Nyst sintetiza el dibujo inicial de Palazuelo y fija una suerte de 'guión' gráfico a partir del que el UPIC realizará su lectura. Como ejemplo pueden destacarse las figuras que ofrece $E l$ Paseante (Palazuelo \& Nyst, 1986) en las que se extracta el proceso gráfico que sigue 
el compositor: puede observarse cómo la segunda figura es el resultado de un gesto, trazado en negro, marcado previamente sobre una de las piezas del ciclo El número y las aguas a partir de las líneas quebradas características del mismo. Este objeto visual es transformado en un gesto gráfico complejo en el que las líneas o segmentos han pasado a convertirse en bloques que serán traducidos al ámbito sonoro por la Unidad Poliagógica. Obviamente el proceso técnico deja poca capacidad creativa en manos del compositor, que se convierte en gestor de la traducción realizada por el aparato. En este caso, la traslación estrictamente gráfica de la obra palazueliana da como resultado un objeto sonoro posiblemente muy cercano al origen pero en el que no existe la ponderación musical, es decir, la conciencia compositiva: no hay planteamiento creativo por parte de Nyst, lo que reduce las posibilidades de lectura y análisis del producto final como objeto musical. En este sentido, la relación interdisciplinar queda establecida en el ámbito estrictamente neutro o gráfico: no hay planteamiento conceptual compartido que justifique una relación poética, puesto que Nyst no interviene como creador autónomo, ni una propuesta sonora que establezca un vínculo estésico relacionado con dicho planteamiento.

Por tanto, a la pregunta formulada anteriormente en la que el compositor belga se cuestionaba la posibilidad de acercar las sintaxis propias de cada uno de los dos artistas, habría que responder que, teniendo en cuenta que Nyst no pone en juego los rasgos que definen su individualidad creadora, no pueden establecerse relaciones o acercamientos entre ambas sintaxis: por definición, cada personalidad artística contempla la necesidad de establecer un lenguaje en el que se definan una serie de componentes que pasan a convertirse en los pilares distintivos de dicho lenguaje. Cuando se plantea la posibilidad de vincular la creación de artistas distintos hacia la consecución de una obra final, estos lenguajes deben coexistir y concertarse para que de una forma u otra puedan ser objeto de análisis, estudio y percepción en la propia obra. En este caso, es la personalidad de Palazuelo la que define desde el inicio el procedimiento de creación de la composición musical; es necesaria la intervención de Nyst pero ésta se instala en un dominio técnico menos creativo, algo manifiesto en el resultado sonoro final.

En otro orden se encuentra la obra musical del compositor José María SánchezVerdú (Algeciras, 1968); en ella podemos encontrar una atracción ineludible y un conocimiento muy preciso del corpus palazueliano, al que dedica varias de sus creaciones (Ordóñez, 2011).

Sin duda, esta obra sí que debe entenderse como una ocasión poco habitual en la que a partir de un objeto visual consigue establecerse una obra musical, desde los presupuestos estéticos que esta actuación comporta y con las consecuencias efectivas que plantea.

\section{Estesis de Palazuelo}

El tercero de los tres niveles en que puede dividirse el análisis de una obra artística $\mathrm{y}$, en el caso que nos ocupa, de la dimensión temporal y musical en la creación de Pablo Palazuelo, es el estésico, que se instala en el momento final de la percepción de la obra. 
Una forma primaria de materialización del fenómeno estésico es el título de la pieza (Nattiez, 1990, 128 y ss.), algo que puede ayudarnos a establecer, en primera instancia, los vínculos y relaciones existentes entre las tres categorías ya establecidas.

En este sentido y si continuamos en un nivel primario, existen en el catálogo de Palazuelo varias referencia directas a magnitudes adscritas al tiempo o a eventos que transcurren ineludiblemente en un flujo temporal. Así ocurre con obras como Alborada (1952) (Rey García et al., 2001, 211-213), Automnes (1952), Metamorphosis I (195556), Mandala (I, 1958 y II, 1965), Rio (1961), Temps blanc (1958) y Tempo (19601970).

El proceso estésico es, sin embargo, algo más complejo que la alusión nominal de orden temporal que un autor pueda realizar. Es la forma en que se recibe por parte del espectador una poética y práctica artística concreta.

En el caso de El número y las aguas, y como etapa final, los ciclos Vinculum Amoris y Arrán, la referencia musical se sustenta en la dimensión temporal interna, y volvemos al discurso que el propio Palazuelo acoge sobre el tiempo. Esta dimensión se construye sobre los conceptos de vibración, resonancia y ritmo. Lo que lleva a pensar a Palazuelo en la posibilidad de la transcripción sonora de sus dibujos es la carga estructural de los mismos, su semiología interna -que viene además promovida por el número, que garantiza o comporta esta coherencia interna a través de la geometría (Palazuelo \& Nyst, 1986, 60-67)- y su comportamiento como lenguaje, que lo asemeja a la partitura musical convencional en la que las grafías se comportan efectivamente como signos musicales con una interpretación precisa.

En todas ellas, como ocurre con las familias de El número y las aguas, Segundo Cantoral y Arran (1990), la línea es un 'elemento engendrador' (Brett, 2007, 235), según afirma Guy Brett:

Resulta claro que características de notación, escritura, cartografía y ornamento y los rastros, automáticamente registrados, de alguna forma de energía cinética, se amalgaman en un campo de fuerzas integradas. (...) Parece haber una lucha entre la capacidad de la línea para sugerir la profundidad y su papel como signo en el plano (...). No está claro si estas líneas son figuras positivas o vacíos negativos, si separan formas o son el agente de la transformación recíproca. (Ibíd.).

La línea es así concebida bien como 'figura positiva' bien como 'vacío negativo', aunque siempre como germen estructural a partir del que se crean nuevos procesos plásticos y procesos rítmicos perceptibles por parte del espectador.

\section{A modo de conclusión}

La abstracción a través de estructuras geométricas, denominada abstracción fría (Bonet et al., 2003; Alés, 2003) también por Palazuelo, lleva a la creación de todo un proceso sígnico que, más allá de su traslación sonora efectiva por parte de otro creador - un compositor, en el caso de Nyst-, establece un alfabeto 'musical', es decir, un lenguaje notacional que puede ser concebido desde su dimensión sonora. Teniendo en cuenta la historiografía relativa al pintor madrileño, hay que decir que la alusión 
a lo musical es recurrente sólo cuando existe el ritmo geométrico abstracto. En este sentido, podría afirmarse que la abstracción es el punto donde pueden converger las direcciones plástica y sonora (Bozal, 2005) siempre y cuando se observe una coherencia interna, una suerte de lenguaje sígnico en el que aun de forma balbuciente existan formas que podrían denominarse 'retóricas' (Grandas, 2007, 22). Como afirma Palazuelo, 'la música es una forma de la geometría' (Palazuelo \& Power, 1995, 57 y ss.).

Asimismo y como hemos podido observar, la obra de Palazuelo alcanza una dimensión temporal obvia tanto en un nivel poiético como en el gráfico y estésico final; desde el corpus conceptual sobre el que el pintor construye su aparato teórico -en el que David Bohm y Xavier Zubiri tienen una relevancia notable- hasta la materialización gráfica -en series como Segundo Cantoral o El número y las aguas- y la percepción por parte del espectador, existe una conciencia temporal precisa y bien definida, lo que justificaría un mayor detenimiento analítico.

Finalmente, lo musical aparece íntimamente relacionado a lo temporal como aplicación efectiva, ya sea en la 'traducción' literal realizada por Frederic Nyst ya sea en la conciencia sígnica y simbólica que la representación gráfica de lo sonoro comporta.

La creación pictórica de Pablo Palazuelo se inscribe definitivamente en una dimensión temporal que es necesario conocer puesto que define su condición estética. Más allá de la temporalidad en la visualización de sus obras, el parámetro tiempo debe situarse en el marco de un estrecho vínculo interdisciplinar con lo musical, a través fundamentalmente de la referencia a las formas de representación gráfica y simbólica del sonido y, posteriormente, a la posibilidad de una traslación directa hacia la realización de un objeto artístico y sonoro de amplio calado conceptual.

Por otro lado, la dimensión temporal nos abre una vía novedosa en el estudio de este artista y de la abstracción geométrica en la que se inscribe, puesto que amplía sus posibilidades hermenéuticas y las proyecta en una dirección compleja de la discusión estética de hoy, cuando los límites interdisciplinares se diluyen y, como afirma Marchán Fiz, la 'poética del desbordamiento' y la 'permeabilidad' de los géneros artísticos se constituyen en rasgo distintivo (Marchán Fiz, 2003).

\section{Referencias}

Arnaldo, J. et al. (2003). Analogías Musicales: Kandinsky y sus contemporáneos. Catálogo de Exposición, Madrid, Fundación Colección Thyssen-Bornemisza.

Bergson, H. (1977). Memoria y vida. Textos escogidos por Gilles Deleuze, Madrid: Alianza Editorial.

Bohm, D. y J. K. (1987). El futuro de la humanidad: diálogos entre Krishnamurti y David Bohm, Barcelona: EDHASA. . (1996). Más allá del tiempo, Barcelona: Kairos. . (2006). Los límites del pensamiento, Barcelona: Kairos.

Bohm, D. (1994). Thought as a system, Londres: Routledge.

Bonell, C. (2006). La geometría y la vida. Antología de Pablo Palazuelo. Murcia: CENDEAC. 
Bonet, J. M. et al. (2003). Eusebio Sempere (1924-1985), Catálogo de la exposición, Arte Español para el Exterior, Madrid, Sociedad Estatal para la Acción Cultural Exterior.

Bosseur, J. Y. (1998). Musique et arts plastiques: interactions au XXe Siècle, Paris: Minerve.

Bozal, V. (2000). Arte del siglo XX en España II, Pintura y escultura, 1939-1990, Madrid: Espasa.

et alt. (2005). El arte abstracto. Los dominios de lo invisible, Madrid: Fundación Cultural Mapfre Vida.

Calvo Serraller, F. (1985). 'Nulla æsthetica sine ethica'. Vanguardia artística y vanguardia política en la década de los sesenta, en F. Calvo Serraller, España. Medio Siglo de Arte de Vanguardias, Madrid, Fundación Santillana, 65-88.

Castaños Alés, E. (2003). Los orígenes del arte cibernético en España: el seminario de generación automática de formas plásticas del centro de cálculo de la Universidad de Madrid, Málaga: Universidad de Málaga.

García, E. R. et al. (2001). Alborada, Emilio Casares (ed.), Diccionario de Música Española e Hispanoamericana, vol. I, 211-212.

Gómez de Liaño, I., Díaz Cuyás, J., Brett B. y Grandas T. (2007). Palazuelo. Proceso de trabajo. Barcelona: Museo de Arte Contemporáneo de Barcelona.

Gullón, R. (1972). 'Proyecto para la Escuela de Altamira', en su libro De Goya al arte abstracto, Madrid: Seminarios y Ediciones, 175-190.

Jarauta, F., López Albaladejo,J. y Torres Nadal, J. M a (dirs.). (1998).Pablo Palazuelo. Escritos, Conversaciones, Murcia, Colegio Oficial de Aparejadores y Arquitectos técnicos. Cedido por la Fundación Pablo Palazuelo.

Johnson, S. (ed.). (2002). The New York schools of music and visual arts: John Cage, Morton Feldman, Edgar Varèse, Willem de Kooning, Jasper Jones, Robert Rauschenberg, New York: Routledge.

Marchán Fiz, S. (2003). Figuras de la mezcla en las artes, en Correspondencia e integración de las artes, Isidoro Coloma Martín y Juan Antonio Sánchez López (eds.), 2 vols., XIV Congreso Nacional de Historiadores del Arte, Málaga, Ministerio de Educación, Cultura y Deportes, Dirección de Comunicación y cooperación cultural, II ${ }^{\circ}$ vol., pp. 19-35.

Nattiez, J-J. (1975). Fondements d'une sémiologie de la musique, Paris: Union Générale d'Éditions.

. (1990). Music and discourse: Toward a semiology of music, Princeton, New Jersey: Princeton University Press.

. (2010). La musique, les images et les mots. Du bon et du moins bon usage des métaphores dans l'esthétique comparée, Quèbec: Fidès.

Ordóñez, P. (2011). La creación musical de Mauricio Sotelo y José María SánchezVerdú: convergencia interdisciplinar a comienzos del siglo XXI, Granada: Universidad de Granada. 
Palazuelo, P. y K. P. (1995). Geometría y visión: Pablo Palazuelo. Granada: Diputación de Granada.

Palazuelo, P. y F. Nyst. (1986). 'El número y las aguas', El Paseante, $n^{\circ} 4,54-73$.

Power, K. (2005). Pablo Palazuelo. La imaginación activa, en Pablo Palazuelo: 1995-2005, Catálogo de exposición, Madrid, MNCARS, 14-37.

Roy-Gerboud, F. (2009). La musique comme Art total au XXe Siècle, Paris: L'Harmattan.

Vergo, P. (2010). The music of painting. Music, Modernism and the Visual Arts from Romantics to John Cage, London: Phaidon Press.

Villa Rojo, J. (2003). Notación y grafia musical en el s. XX, Madrid: Iberautor.

Zubiri, X. (1995). Estructura dinámica de la realidad, Madrid: Alianza Editorial. . (1998). La inteligencia sentiente, Madrid: Alianza Editorial. 